\title{
Factors Predictive of Sentinel Lymph Node Involvement in Primary Breast Cancer
}

\author{
WOLFRAM MALTER ${ }^{1}$, MARTIN HELLMICH ${ }^{2}$, MAYHAR BADIAN ${ }^{3}$, \\ VERENA KIRN $^{1}$, PETER MALLMANN $^{4}$ and STEFAN KRÄMER ${ }^{5}$ \\ ${ }^{1}$ Breast Center, ${ }^{2}$ Institute of Medical Statistics, Informatics and Epidemiology, \\ ${ }^{4}$ Department of Gynaecology and Obstetrics, University Medical Center of Cologne, Cologne, Germany; \\ ${ }^{3}$ Western German Breast-Center, DOC Holding GmbH, Düsseldorf, Germany; \\ ${ }^{5}$ Department of Gynaecology and Obstetrics, Helios Hospital Krefeld, Krefeld, Germany
}

\begin{abstract}
Background/Aim: Sentinel lymph node biopsy $(S L N B)$ has replaced axillary lymph node dissection $(A L N D)$ for axillary staging in patients with early-stage breast cancer. The need for therapeutic ALND is the subject of ongoing debate especially after the publication of the ACOSOG Z0011 trial. In a retrospective trial with univariate and multivariate analyses, factors predictive of sentinel lymph node involvement should be analyzed in order to define tumor characteristics of breast cancer patients, where SLNB should not be spared to receive important indicators for adjuvant treatment decisions (e.g. thoracic wall irradiation after mastectomy with or without reconstruction). Patients and Methods: Between 2006 and 2010, 1,360 patients with primary breast cancer underwent SLNB with/without ALND with evaluation of tumor localization, multicentricity and multifocality, histological subtype, tumor size, grading, lymphovascular invasion (LVI), and estrogen receptor, progesterone receptor and human epidermal growth factor receptor 2 status. These characteristics were retrospectively analyzed in univariate and multivariate logistic regression models to define significant predictive factors for sentinel lymph node involvement. The multivariate analysis demonstrated that tumor size and LVI $(p<0.001)$ were independent predictive factors for metastatic sentinel lymph node involvement in patients with early-stage breast cancer. Conclusion: Because of the increased risk for metastatic involvement of axillary sentinel nodes in cases with larger breast cancer or diagnosis of LVI, patients with these breast cancer characteristics should not be spared from $S L N B$ in a
\end{abstract}

Correspondence to: Wolfram Malter, MD, Breast Center, Department of Gynaecology and Obstetrics, Kerpener Str. 34, 50931 Cologne, Germany. E-mail: wolfram.malter@uk-koeln.de

Key Words: Breast cancer, sentinel node biopsy, predictive factors, lymph node involvement. clinically node-negative situation in order to avoid falsenegative results with a high potential for wrong indication of primary breast reconstruction or wrong non-indication of necessary post-mastectomy radiation therapy. The prognostic impact of avoidance of axillary staging with $S L N B$ is analyzed in the ongoing prospective INSEMA trial.

The axillary lymph nodes are the primary site of lymphatic drainage from all areas of the breast. The extent of axillary lymph node involvement in breast cancer has been recognized as the strongest predictor of recurrence and survival, as the extent of lymph node involvement increases, survival decreases regardless of tumor size $(1,2)$.

Axillary lymph node dissection (ALND) has been an integral part of the surgical management of breast cancer since the description of radical mastectomy by Halstedt in 1894 (3). Although ALND reliably stages the axilla and is an effective method for local control, it is of no benefit to women whose axillary lymph nodes do not contain metastases. This radical surgical method is associated with significant long-term complications, including lymphedema, sensory morbidity and restriction in shoulder functionality (4).

Surgical management of the axilla changed radically with the introduction of the sentinel lymph node biopsy (SLNB) in the early 1990s (5, 6). Patients with node-negative breast cancer can be spared the morbidity of ALND. However, if the sentinel node is found to have metastatic involvement, completion ALND is routinely performed. Metastatic involvement is histologically analyzed with serial sectioning and immunohistochemistry (IHC) staining to identify macrometastases, micrometastases, and isolated tumor cells.

While in the NSABP B32 trial, investigating axillary resection with sentinel node dissection, $16 \%$ of the 3,986 patients with SLN-negative disease had micrometastatic involvement of the axillary lymph nodes, $11 \%$ of these patients also had isolated tumor cells (pNOi+). Because most of these patients received systemic adjuvant therapy, it is 
clear that fewer than $1 \%$ of patients would have experienced a survival benefit from routine ALND (7).

Despite all the evidence supporting the need for ALND in patients with macrometastatic involvement of a SLN, The American College of Surgical Oncology Group (ACOSOG) Z0011 trial was performed to examine the role of ALND in clinically node-negative patients found to have macrometastatic involvement of one or two SLNs. All patients underwent treatment with lumpectomy, radiation therapy, and adjuvant systemic therapy. At a median of 6.3 years of follow-up, there were no significant differences between the sentinel lymph node-only and the ALND groups in the rates of overall locoregional recurrence. The 5-year survival rates for patients without and with IHC-detected metastases did not differ significantly (95.8\% vs. 95.1\%; $p=0.53)$ (8). Additionally, neither disease-free nor overall survival differed significantly between groups. As a clinical consequence, ALND is no longer recommended when there is macrometastatic involvement of one or two SLNs (clinically node-negative) and patients fulfil the eligibility criteria of the ACOSOG Z0011 trial (9).

More recently, it has been recognized that breast cancer is not a uniform disease but a group of different molecular intrinsic subtypes with differing prognoses (10). Between these subtypes, the incidence of lymph node metastasis differs (11). Several predictors of lymph node metastasis have been described such as multifocality, higher histological grade, lateral and retroareolar location of the tumor, larger tumor size and the presence of lymphovascular invasion (LVI) (12). The predictive role of estrogen receptor (ER) and progesterone receptor (PR) expression and human epidermal growth factor receptor 2 (HER2) status, histological subtype and age remains controversial (13-16).

The goal of our study was to determine prognostic and predictive factors associated with SLN metastases in patients with primary breast cancer in order to derive future evidence to define a clinically node-negative patient subgroup where SLNB might not be recommended.

\section{Patients and Methods}

Patients. Data were obtained from the database of the Breast Center of the Department of Gynecology and Obstetrics, University Medical Center of Cologne, Germany. Between October 2006 and December 2010, 1,360 patients with primary invasive breast cancer (cT1-cT3) underwent resection of the primary tumor and axillary staging by SLNB. An ALND was performed if required by gold standard. The local treatment consisted of wide excision followed by adjuvant wholebreast radiotherapy or mastectomy with or without radiotherapy (according to national guidelines). Patients treated for local recurrence, with carcinoma in situ only, who received neo-adjuvant therapy were diagnosed with primary metastatic disease were excluded.

Predictive factors. In order to determine factors associated with metastatic involvement of SLNs, each of the following parameters were evaluated: age at diagnosis, histological subtype, tumor size, histological
Table I. Clinical and pathological characteristics of analyzed patients $(n=1,360)$.

\begin{tabular}{|c|c|}
\hline Characteristic & Value \\
\hline \multicolumn{2}{|l|}{ Age } \\
\hline Range (years) & $23-89$ \\
\hline Mean (years) & 57.0 \\
\hline \multicolumn{2}{|l|}{ Number of foci, $\mathrm{n}(\%)$} \\
\hline Unifocal & $1256(91.8)$ \\
\hline Multifocal & $113(8.2)$ \\
\hline \multicolumn{2}{|l|}{ Histological grade, n (\%) } \\
\hline 1 & $39(2.8)$ \\
\hline 2 & $985(72.0)$ \\
\hline 3 & $311(22.7)$ \\
\hline Unknown & $34(2.5)$ \\
\hline \multicolumn{2}{|l|}{ Tumor location, n (\%) } \\
\hline Upper outer & $941(68.7)$ \\
\hline Upper inner & $167(12.2)$ \\
\hline Lower outer & $122(8.9)$ \\
\hline Lower inner & $79(5.8)$ \\
\hline Central & $30(2.2)$ \\
\hline Overlapping & $15(1.1)$ \\
\hline Unknown & $7(1.1)$ \\
\hline \multicolumn{2}{|l|}{ Histological subtype, n (\%) } \\
\hline Invasive ductal/DCIS & $1015(74.1)$ \\
\hline Invasive lobular & $162(11.8)$ \\
\hline Invasive ductal and lobular & $24(1.8)$ \\
\hline Other & $149(10.9)$ \\
\hline Unknown & $19(1.4)$ \\
\hline \multicolumn{2}{|c|}{ Axillary lymph node dissection, n (\%) } \\
\hline No & $1079(78.8)$ \\
\hline Yes & $281(20.5)$ \\
\hline Unknown & $9(0.7)$ \\
\hline \multicolumn{2}{|l|}{ Tumor size, n (\%) } \\
\hline $\mathrm{T} 1 \mathrm{a} / \mathrm{b}$ & $285(20.8)$ \\
\hline $\mathrm{T} 1 \mathrm{c}$ & $561(41.0)$ \\
\hline $\mathrm{T} 2$ & $372(27.2)$ \\
\hline $\mathrm{T} 3$ & $41(3.0)$ \\
\hline Unknown & $110(8.0)$ \\
\hline \multicolumn{2}{|l|}{ Nodal status, n (\%) } \\
\hline pNO & 1079 \\
\hline $\mathrm{pN} 1$ & $240(78.8)$ \\
\hline pN2-3 & $48(3.5)$ \\
\hline Unknown & $2(0.2)$ \\
\hline \multicolumn{2}{|l|}{ ER status, n (\%) } \\
\hline Positive & $1145(83.6)$ \\
\hline Negative & $206(15.0)$ \\
\hline Unknown & $18(1.4)$ \\
\hline \multicolumn{2}{|l|}{ PR status, n (\%) } \\
\hline Positive & $1068(78.0)$ \\
\hline Negative & $283(20.7)$ \\
\hline Unknown & $18(1.3)$ \\
\hline \multicolumn{2}{|l|}{ HER2 status, n (\%) } \\
\hline Positive & $147(10.7)$ \\
\hline Negative & $1175(85.8)$ \\
\hline Unknown & $47(3.5)$ \\
\hline \multicolumn{2}{|l|}{ LVI, n (\%) } \\
\hline Positive & $271(19.8)$ \\
\hline Negative & $1027(75.0)$ \\
\hline Unknown & $71(5.2)$ \\
\hline
\end{tabular}

DCIS: Ductal carcinoma in situ; ER: estrogen receptor; HER2: human epidermal growth factor receptor 2; LVI: lymphovascular invasion; PR: progesterone receptor. 
Table II. Univariate analysis of characteristics.

\begin{tabular}{|c|c|c|c|}
\hline Variable & Comparison & Odds ratio $(95 \% \mathrm{CI})$ & $p$-Value \\
\hline Age & Per decade & $0.93(0.83-1.04)$ & 0.210 \\
\hline Number of foci & Unit increase & $1.61(1.06-2.48)$ & 0.027 \\
\hline \multirow[t]{3}{*}{ Histological grade } & $1 v s .2$ & $1.44(0.89-2.33)$ & 0.143 \\
\hline & 1 vs. 3 & $1.61(0.93-2.72)$ & 0.07 \\
\hline & $2 v s .3$ & $1.12(0.83-1.53)$ & 0.46 \\
\hline \multirow[t]{5}{*}{ Tumor location } & Upper outer $v s$. central & $2.08(0.97-4.40)$ & 0.059 \\
\hline & Upper outer $v s$. upper inner & $0.69(0.45-1.08)$ & 0.012 \\
\hline & upper outer $v s$. lower inner & $0.77(0.43-1.41)$ & 0.399 \\
\hline & upper outer $v s$. lower outer & $0.93(0.58-1.48)$ & 0.744 \\
\hline & Upper outer $v s$. overlapping and retroareolar & $2.11(1.13-3.95)$ & 0.019 \\
\hline \multirow[t]{5}{*}{ Tumor size } & $\mathrm{T} 1$ & $2.80(2.11-3.72)$ & 0.001 \\
\hline & $\mathrm{T} 2$ & $5.23(2.76-9.93)$ & 0.001 \\
\hline & $\mathrm{T} 3$ & $10.89(0.99-122.0)$ & 0.51 \\
\hline & Ductal $v s$. lobular & $1.125(0.76-1.65)$ & 0.549 \\
\hline & Ductal vs. other & $0.378(0.23-0.62)$ & 0.001 \\
\hline LVI & Present $v s$. absent & $3.62(2.54-5.13)$ & 0.001 \\
\hline ER status & Positive $v s$. negative & $1.187(0.815-1.73)$ & 0.372 \\
\hline PR status & Positive $v s$. negative & $1.125(0.812-1.56)$ & 0.478 \\
\hline HER2 status & Positive $v s$. negative & $1.32(0.89-1.95)$ & 0.161 \\
\hline
\end{tabular}

ER: Estrogen receptor; HER2: human epidermal growth factor receptor 2; LVI: lymphovascular invasion; PR: progesterone receptor.

nuclear tumor grade, number of SLNs removed, IHC of ER and PR, HER2 status, LVI, the number of patients receiving only SLNB, or ALND following SLNB. Univariate and multivariate analyses were performed. Factors significantly associated with metastatic involvement of SLN in univariate analysis were included in the multivariate model.

SLN detection. The SLNs were preoperatively marked by injecting a radioactive isotope ( ${ }^{99} \mathrm{~m} T \mathrm{c}$-labelled nanocolloid) into Sappey's subareolar plexus (17). The SLNs were identified with a hand-held gamma detector (Neoprobe ${ }^{\circledR}$; Ethicon Endosurgery, Cincinnatti, OH, USA) before surgical removal.

Histological examination of SLNs. SLNs were routinely examined by serial sectioning. Every $200 \mu \mathrm{m}$, two sections were stained, one with routine hematoxylin and eosin (H\&E) and one by IHC using cytokeratin. Lymph nodes in ALND specimens were examined by H\&E staining using three sections per node. According to gold standard, lymph nodes from lobular breast cancer classified as lymph node-negative on $\mathrm{H} \& \mathrm{E}$ were additionally stained for IHC examination of E-cadherin.

Statistical methodology. To analyze the effect of various predictors on the presence or absence of positive ALNs, logistic regression models were used. Univariate analysis was performed for a number of predictors of which a relationship to lymph node involvement was to be expected. Thereafter, a multivariate analysis was performed including those predictors that were shown to be related in the univariate analysis. Odds ratios and $p$-values were calculated. The $95 \%$ confidence intervals $(\mathrm{CI})$ were calculated and pair-wise comparison between groups was made to determine which results were statistically significant. All $p$-values smaller than 0.05 were used for statistical significance. All analyses were performed using SPSS software version 22.0 (IBM Corp., Armonk, NY, USA).

\section{Results}

Between October 2006 and December 2010, SLNB was performed in 1,360 patients with unilateral breast cancer, and in 38 patients with bilateral breast cancer.

Table I shows the clinical and pathological characteristics of the patients. The mean age was 57 years (range $=23-89$ years). Of the patients who underwent SLNB, 281 patients (20.5\%) were lymph node-positive and underwent ALND according to gold standard at the time (18). A total of 846 $(61.8 \%)$ had a T1 tumor size, $1,145(83.6 \%)$ patients were ER-positive, while 147 (10.7\%) of the patients had HER2positive breast cancer. LVI was histologically detected in 271 (19.8\%) patients. For patients whose characteristics were not present in records, these data were summarized as unknown.

Results of the univariate analyses are presented in Table II. There was a significant association of number of tumor foci with $\mathrm{ALN}$ involvement $(\mathrm{OR}=1.61,95 \% \mathrm{CI}=1.06-2.48$; $p=0.027$ ). There was an overall effect of tumor grade, the higher the tumor grade, the higher the probability of ALN metastasis.

Patients with grade 2 tumors were found to have a lower probability of ALN metastasis compared to patients with grade 3 tumors $(\mathrm{OR}=1.12,95 \% \mathrm{CI}=0.83-1.53 ; p=0.46)$ and patients with grade 1 tumors had the lowest probability of ALN metastasis (grade $1 v s$. grade 3 : $\mathrm{OR}=1.61, \mathrm{CI}=0.93$ $2.72 ; p=0.07$ ), without statistical significance.

The tumor location was also found to have a statistically significant effect on nodal involvement. Patients with tumors 
of the upper outer quadrant had a higher probability of positive ALNs compared to patients with tumors of the upper inner quadrant $(\mathrm{OR}=0.69,95 \% \mathrm{CI}=0.45-1.08 ; p=0.012)$. However, patients with a retroareolar tumor localization had a higher probability of positive ALNs (OR=2.11, 95\% $\mathrm{CI}=1.13-3.95 ; p=0.019)$.

According to tumor size, the risk for ALN metastasis steadily increased from the smallest to the largest tumors $(\mathrm{OR}=5.23,95 \% \mathrm{CI}=2.76-9.93 ; p<0.001)$ Furthermore, there was a highly significant effect of LVI. Patients with LVI had a much higher probability of positive ALNs compared to patients without LVI $(\mathrm{OR}=3.62,95 \% \mathrm{CI}=2.54-5.13 ; p<0.001)$.

Subsequently, multivariate analysis was carried out on those variables found to be statistically significant in univariate analyses to analyze for significant independence as predictive markers for ALN involvement. Moreover, histological subtype was included as we found the histological subtype to be a predictive factor for lymph node involvement (Table II). The results of multivariate analysis are presented in Table III.

LVI and tumor size were found to be the most powerful predictors of nodal status $(p<0.001)$. All other variables (tumor localization, histological subtype) of the univariate analyses were found not to be independently significant in the multivariate analyses.

\section{Discussion}

Since the introduction of SLNB as a staging procedure for the ALN status, the role of ALND has decreased worldwide (17). Today, SLNB is a well-established procedure for axillary staging, with a false-negative rate lower than $5 \%$, as well as its higher pathological accuracy for the detection of occult lymph node metastases in the SLN (micrometastasis, isolated tumor cells) (19-21). The therapeutic benefit of ALND is much more controversially discussed. In the NSABP-B04 study, ALND was not able to improve overall survival in patients with breast cancer, underlining that breast cancer is a systemic disease from its onset such that removing involved or uninvolved ALNs is unlikely to affect survival (22). On the other hand, a meta-analysis of the Early Breast Cancer Trialists' and Collaborative Group demonstrated that improved locoregional control in patients with early-stage breast cancer translated into a survival benefit after 15-year follow-up (23).

The results of the ACOSOG Z0011 trial suggest that ALND should be avoided in patients with 1-2 macrometastatically involved SLNs who are treated with breast-conserving surgery, whole-breast irradiation and adjuvant systemic therapy (9). Moreover, the debate on the role of therapeutic ALND is still ongoing because of some limitations of that trial regarding the completeness of accrual, adherence to the scheduled surgical treatment and the applied radiotherapy (24). In recent years, several mathematical models (nomograms)
Table III. Multivariate analysis of characteristics.

\begin{tabular}{ll}
\hline Variable & $p$-Value \\
\hline Tumor location & 0.602 \\
Tumor size & 0.0001 \\
Histological type & 0.243 \\
Lymphovascular invasion & 0.0001 \\
\hline
\end{tabular}

have been developed which can be used to predict lymph node involvement based on SLNB results. These nomograms are based on tumor-related characteristics such as tumor subtype, size, LVI, grading, and hormone receptor status (25). However, these nomograms lack sufficient accuracy and have limited clinical practicability. As a matter of fact, in the ACOSOG Z0011 trial, more than $25 \%$ of patients in the SLNonly arm had involved axillary non-SLNs left without a negative effect on disease-free or overall survival.

For future clinical practice, the question arises as to whether a subgroup of patients with a low risk for SLN metastases can be defined for whom SLNB can be avoided altogether. This question is being prospectively analyzed in the ongoing INSEMA-trial (NCT02466737). In this trial, in the first part, patients with clinically node-negative earlystage breast cancer are randomized at a one-to-four ratio to no SLNB and SLNB. In the second part, if 1-2 SLNs are found to be involved, patients are randomized to no ALND and ALND (according to the ACOSOG Z0011 protocol).

The status of the axilla is increasingly important for primary reconstruction in order to avoid radiotherapy of the thoracic wall. Furthermore, the risk of LN involvement may influence the timing of breast reconstruction. In patients at low risk of $\mathrm{LN}$ involvement, primary reconstruction after mastectomy can be considered, while in patients at high risk of LN involvement, a second procedure in favor of autologous reconstruction may be preferred. In clinical practice, in order to exclude the necessity for postmastectomy radiation therapy when primary implant reconstruction is planned, we recommend pre-therapeutic SLNB. The detection of metastatic involvement of a SLN is an indication for post-mastectomy radiation therapy and a relative contraindication for primary implant reconstruction because of an increased incidence of capsular fibrosis (26).

In our analysis, the presence of $\mathrm{LN}$ metastasis in 1,360 patients with breast cancer $(21.9 \%)$ is not in accordance with the incidence range reported in literature (33.2-39\%). Three parameters emerged as dependent predictors of the ALN status in univariate analyses, namely the number of foci, tumor location, primary tumor size and LVI. The age of the patient at diagnosis and histological grade did not retain significance in univariate analyses. These results are largely in concordance with other series published in the literature $(27,28)$. 
LVI has been described as the strongest independent predictor of nodal involvement (29). This finding was confirmed in the present study. Of our patients with LVI, $75.0 \%$ had positive ALNs. In our series, tumor size was the second strongest dependent predictive factor. Tumor size has also been shown to be an independent factor in various studies $(30,31)$. For example, in patients with tumors smaller than $10 \mathrm{~mm}, 15.4 \%$ were found to be lymph node-positive after SLNB, while $33.8 \%$ of patients with tumor sizes between $20 \mathrm{~mm}$ and $50 \mathrm{~mm}$ were so.

Our results will not alter the indications for SLNB. Even patients with a high probability of $\mathrm{LN}$ involvement are candidates for SLNB as a subgroup of these patients can safely avoid an ALND.

Finally, this study cannot be used to predict the tumor load in the axilla. There is an ongoing debate on the prognostic implications of minimal LN involvement. With the introduction of SLNB, there was an upstaging of a subgroup of patients. These patients have mainly isolated tumor cells or micrometastasis in the SLN due to a more detailed histological examination. However, our model for predicting ALN involvement cannot differentiate between micro- or macrometastatic disease in the axilla (data not shown). LVI and tumor size emerged as the most powerful independent predictors of ALN metastasis, followed by the location of the tumor in the breast and the histological subtype.

These results can be used for decision making in clinical practice and should be further prospectively analyzed in the ongoing INSEMA trial. The information regarding involved SLNs is important to indicate the need for postoperative radiotherapy of the thoracic wall after mastectomy with or without primary reconstruction of the breast. The avoidance of SLNB in all patients with early-stage breast cancer can negativity affect the prognosis of some patients, when postoperative radiation therapy necessary after mastectomy (including skin- or nipple-sparing mastectomy with reconstruction) cannot be indicated.

\section{References}

1 Carter CL, Allen C and Henson DE: Relation of tumor size, lymph node status, and survival in 24,740 breast cancer cases. Cancer 63: 181-187, 1989.

2 Yoshihara E, Smeets A, Laenen A, Reynders A, Soens J, Van Ongeval C, Moerman P, Paridaens R, Wildiers H, Neven P and Christiaens MR: Predictors of axillary lymph node metastases in early breast cancer and their applicability in clinical practice. Breast 22: 357-361, 2013.

3 Halsted WS: The results of operations for the cure of cancer of the breast performed at the Johns Hopkins Hospital from June 1889 to January 1894. Ann Surg 20: 497-555, 1894.

4 McLaughlin SA, Wright MJ, Morris KT, Giron GL, Sampson MR, Brockway JP, Hurley KE, Riedel ER and Van Zee KJ: Prevalence of lymphedema in women with breast cancer 5 years after sentinel lymph node biopsy or axillary dissection: objective measurements. J Clin Oncol 26: 5213-5219, 2008.

5 Giuliano AE, Kirgan DM, Guenther JM and Morton DL: Lymphatic mapping and sentinel lymphadenectomy for breast cancer. Ann Surg 220: 391-398, 1994.

6 Veronesi U, Viale G, Paganelli G, Zurrida S, Luini A, Galimberti V, Veronesi P, Intra M, Maisonneuve P, Zucca F, Gatti G, Mazzarol G, De Cicco C and Vezzoli D: Sentinel lymph node biopsy in breast cancer: Ten-year results of a randomized controlled study. Ann Surg 251: 595-600, 2010.

7 Krag DN, Anderson SJ, Julian TB, Brown AM, Harlow SP, Costantino JP, Ashikaga T, Weaver DL, Mamounas EP, Jalovec LM, Frazier TG, Noyes RD, Robidoux A, Scarth HM and Wolmark N: Sentinel-lymph-node resection compared with conventional axillary-lymph-node dissection in clinically nodenegative patients with breast cancer: overall survival findings from the NSABP B-32 randomised phase 3 trial. Lancet Oncol 11: 927-933, 2010.

8 Giuliano AE, Hawes D, Ballman KV, Whitworth PW, Blumencranz PW, Reintgen DS, Morrow M, Leitch AM, Hunt KK, McCall LM, Abati A and Cote R: Association of occult metastases in sentinel lymph nodes and bone marrow with survival among women with early-stage invasive breast cancer. J Am Med Assoc 306: 385-393, 2011.

9 Giuliano AE, Hunt KK, Ballman KV, Beitsch PD, Whitworth PW, Blumencranz PW, Leitch AM, Saha S, McCall LM and Morrow M: Axillary dissection vs. no axillary dissection in women with invasive breast cancer and sentinel node metastasis: a randomized clinical trial. J Am Med Assoc 305: 569-575, 2011.

10 Sørlie T, Perou CM, Tibshirani R, Aas T, Geisler S, Johnsen H, Hastie T, Eisen MB, van de Rijn S, Jeffrey SS, Thorsen T, Quist $\mathrm{H}$, Matese JC, Brown PO, Botstein D, Lønning PE and Børresen-Dale AL: Gene expression patterns of breast carcinomas distinguish tumor subclasses with clinical implications. Proc Natl Acad Sci 98: 10869-10874, 2001.

11 Morrow M: Personalizing extent of breast cancer surgery according to molecular subtypes. Breast 22(Suppl 2): 106-109, 2013.

12 Viale G, Zurrida S, Maiorano E, Mazzarol G, Pruneri G, Paganelli G, Maisonneuve P and Veronesi U: Predicting the status of axillary sentinel lymph nodes in 4351 patients with invasive breast carcinoma treated in a single institution. Cancer 103: 492-500, 2005.

13 Patani NR, Dwek MV and Douek M: Predictors of axillary lymph node metastasis in breast cancer: a systematic review. Eur J Surg Oncol 33: 409-419, 2007.

14 Chua B, Ung O, Taylor R and Boyages J: Frequency and predictors of axillary lymph node metastases in invasive breast cancer. ANZ J Surg 71: 723-728, 2001.

15 Vandorpe T, Smeets A, Van Calster B, Van Hoorde K, Leunen K, Amant F, Moerman P, Deraedt K, Brouckaert O, Van Huffel S, Wildiers H, Christiaens MR and Neven P: Lobular and nonlobular breast cancers differ regarding axillary lymph node metastasis: a cross-sectional study on 4,292 consecutive patients. Breast Cancer Res Treat 128: 429-435, 2011.

16 Wildiers P, Van Calster B, van de Poll-Franse LV and Hendrickx W, Røislien J, Smeets A, Paridaens R, Deraedt K, Leunen K, Weltens C, Van Huffel S, Christiaens MR and Neven P: Relationship between age and axillary lymph node involvement in women with breast cancer. J Clin Oncol 27: 2931-2937, 2009. 
17 Suami H, Pan WR and Taylor GI: Historical review of breast lymphatic studies. Clin Anat 22: 531-536, 2009.

18 German Guidelines for Gynecology Oncology, status 2010. https://www.ago-online.de/de/infothek-fuer-aerzte/ leitlinienempfehlungen/mamma/februar-2010/

19 Janni W, Kühn T, Schwentner L, Kreienberg R, Fehm T, Wöckel A: Sentinel node biopsy and axillary dissection in breast cancer. Dtsch Ärztebl Int 11: 244-249, 2014.

20 Cserni G: Axillary staging of breast cancer and the sentinel node. J Clin Path 53: 733-741, 2000.

21 Kühn T: Sentinel lymph node biopsy in early breast cancer. Breast Care 6: 185-191, 2011.

22 Fisher B, Jeong JH, Anderson S, Bryant J, Fisher ER and Wolmark $\mathrm{N}$ : Twenty-five-year follow-up of a randomized trial comparing radical mastectomy, total mastectomy, and total mastectomy followed by irradiation, N Engl J Med 347: 567-575, 2002.

23 Clarke M, Collins R, Darby S, Davies C, Elphinstone P, Evans V, Godwin J, Gray R, Hicks C, James S, MacKinnon E, McGale P, McHugh T, Peto R, Taylor C, Wang Y; Early Breast Cancer Trialists' Collaborative Group (EBCTCG): Effects of radiotherapy and of differences in the extent of surgery for early breast cancer on local recurrence and 15-year survival: an overview of the randomised trials. The Lancet 366: 2087-2106, 2005.

24 Giuliano AE, Morrow M, Duggal S and Julian TB: Should ACOSOG Z0011 change practice with respect to axillary lymph node dissection for a positive sentinel lymph node biopsy in breast cancer? Clin Exp Metastasis 29: 687-692, 2012.

25 Wong SL, Edwards MJ, Chao C, Tuttle TM, Noyes RD, Woo C, Cerrito PB, McMasters KM; University of Louisville Breast Cancer Sentinel Lymph Node Study Group: Predicting the status of the nonsentinel axillary nodes: a multicenter study. Arch Surg 136: 563-568, 2001.

26 Negenborn VL, Dikmans REG, Bouman MB, Winters HAH, Twisk JWR, Ruhé PQ, Mureau MAM, Smit JM, Tuinder S, Hommes J, Eltahir Y, Posch NAS, Meesters-Caberg MA, van der Hulst RRWJ, Ritt MJPF and Mullender MG: Predictors of complications after direct-to-implant breast reconstruction with an acellular dermal matrix from a multicentre randomized clinical trial. Br J Surg, 2016. https://doi.org/10.1002/bjs.108652018.
27 Houvenaeghel G, Bannier M, Nos C, Giard S, Mignotte H, Jacquemier J, Martino M, Esterni B, Belichard C, Classe JM, Tunon de Lara C, Cohen M, Payan R, Blanchot J, Rouanet P, Penault-Llorca F and Bonnier P, Fournet S, Agostini A, Marchal $\mathrm{F}$ and Garbay JR: Non sentinel node involvement prediction for sentinel node micrometastases in breast cancer: nomogram validation and comparison with other models. Breast 21: 204209, 2012.

28 Rivers AK, Griffith KA, Hunt KK, Degnim AC, Sabel MS, Diehl KM, Cimmino VM, Chang AE, Lucas PC and Newman LA: Clinicopathologic features associated with having four or more metastatic axillary nodes in breast cancer patients with a positive sentinel lymph node. Ann Surg Oncol 13: 36-44, 2006.

29 Maibenco DC, Weiss LK, Pawlish KS and Severson RK: Axillary lymph node metastases associated with small invasive breast carcinomas. Cancer 85: 1530-1536, 1999.

30 Ravdin PM, De Laurentiis M, Vendely $\mathrm{T}$ and Clark GM: Prediction of axillary lymph node status in breast cancer patients by use of prognostic indicators. J Natl Cancer Inst 132: 384-390, 1994.

31 Seidman JD, Schnaper LA and Aisner SC: Relationship of the size of the invasive component of the primary breast carcinoma to axillary lymph node metastasis. Cancer 75: 65-71, 1995.

Received March 13, 2018

Revised April 29, 2018

Accepted May 3, 2018 